\title{
A ASSOCIAÇÃO DAS ATITUDES DE CHEFES E CLIENTES COM A SATISFAÇÃO DOS VENDEDORES COM O TRABALHO
}

\section{1- Ana Lúcia de Oliva Lima*}

Mestre em Administração pela Fundação Instituto Capixaba de Pesquisa em Contabilidade, Economia e Finanças (FUCAPE), Brasil.

lima.analucia@gmail.com

http://lattes.cnpq.br/6215307534632465

\section{2- Emerson Wagner Mainardes}

Doutor em Administração pela Universidade da Beira Interior (UBI), Portugal.

Professor da Fundação Instituto Capixaba de Pesquisa em Contabilidade, Economia e Finanças (FUCAPE), Brasil. emerson@fucape.br

http://lattes.cnpq.br/9828374447862752

\section{3- Joselita Pancine Vigna}

Mestre em Administração pela Fundação Instituto Capixaba de Pesquisa em Contabilidade, Economia e Finanças (FUCAPE), Brasil.

Professora da Fundação Instituto Capixaba de Pesquisa em Contabilidade, Economia e Finanças (FUCAPE), Brasil. jovigna@gmail.com

http://lattes.cnpq.br/3323278969662532

\author{
Diego Maganhotto Coraiola - Editor Geral \\ Editor responsável pela submissão: \\ Diego Maganhotto Coraiola.
}

Artigo analisado via processo de revisão duplo cego (Double-blind).

Recebido em: 17/05/2016

Aprovado em: 10/06/2016

Última Alteração: 08/07/2016 


\title{
A ASSOCIAÇÃO DAS ATITUDES DE CHEFES E CLIENTES COM A SATISFAÇÃO DOS VENDEDORES COM O TRABALHO ${ }^{1}$
}

\section{RESUMO}

Esta pesquisa pretendeu verificar se as atitudes dos chefes e clientes afetam a satisfação do vendedor com o trabalho. Para tanto, utilizou-se a Escala INDSALES, de autoria de Childers e Ferrell (1979), para trabalhar com duas dimensões dessa escala, os chefes e os clientes. A partir dessas dimensões, foi construído um questionário, envolvendo três construtos, a satisfação com o trabalho, as atitudes dos chefes e as atitudes dos clientes. Os dados coletados junto a 255 vendedores foram analisados usando estatística descritiva e um modelo de regressão linear múltipla. Os resultados do estudo revelaram que a satisfação do vendedor com o trabalho está associada ao chefe colocar em prática as ideias que os vendedores dão no trabalho; ao vendedor não sofrer injustiças vindas do chefe, à demonstração de confiança e a compreensão do seu trabalho por parte do cliente. Concluise, portanto, que esses resultados podem auxiliar os gestores a definirem suas políticas de gestão de vendas considerando as relações entre chefe e vendedor de modo a melhorar a eficácia dessas relações.

\section{Palavras-Chave}

Satisfação com o trabalho; Vendas; INDSALES.

\section{THE ASSOCIATION OF THE ATTITUDES OF CHIEFS AND CLIENTS WITH THE SELLER'S SATISFACTION WITH WORK}

\begin{abstract}
This research investigates whether the attitudes of chiefs and clients affects the satisfaction of sellers with their job. For this, the INDSALES Scale, written by Childers and Ferrell (1979), was used. Two dimensions were worked on this scale, the chiefs and the clients. From this dimensions, a questionnaire was build, involving three circumscriptions: the satisfaction with work, the attitude of chiefs and the attitudes of clients. Data collected from 255 sellers were analyzed using descriptive statistics and a model of multiple linear regression. The results of the study revealed that the satisfaction of the seller with his work is associated whether the chief put in practice the ideas that the sellers give on work, if the sellers do not suffered any injustice by the chiefs, and to the demonstration of confidence and understanding of their work by the customer. As conclusion, these results may help managers to define their policies of sales management considering the relations between chief and seller in order to improve the effectiveness of these relations.
\end{abstract}

\section{Keywords}

Jobsatisfaction; Sales; INDSALES. 


\section{Introdução}

A força de trabalho em vendas é cada vez mais relevante para as empresas. Cientes da crescente importância da força de vendas em uma organização, gerentes estão mais preocupados em manter os vendedores motivados e satisfeitos com o trabalho. Neste contexto, saber sobre a satisfação no trabalho dos profissionais de vendas é algo relevante e um tanto desafiador, ainda mais que os funcionários da área de vendas exercem uma função de "limite" na interface entre a organização e o seu ambiente de mercado (Amyx \& Bhuian, 2009; Churchill, Ford, \& Walker, 1974; Lagace, Goolsby \& Gassenheimer, 1993; Yang, Hansen, Chartrand, \& Fitzsimons, 2013).

Em estudos anteriores, pesquisadorestais como Churchill, Ford, \& Walker (1974) e Amyx \& Bhuian (2009) constataram que a satisfação no trabalho afeta o desempenho do vendedor, o que gera um impacto direto e importante sobre a empresa. Para entender os fatores que afetam e que são afetados por diferentes dimensões da satisfação com o trabalho e para conseguir aplicar práticas gerenciais corretas, algumas empresas têm recorrido ao uso de informações fornecidas por pesquisas baseadas em escalas existentes de mensuração da satisfação no trabalho (Mackenzie, Podsakoff \& Rich, 2001; Rutherford, Boles, Hamwi, Madupalli, \& Rhterford, 2009). Uma dessas escalas é a INDSALES (Salesman Specific job Satisfaction Scale), quefoi utilizada nesse estudo.Apesar de Rutherford et al. (2009) afirmarem que os estudos sobre a satisfação com o trabalho sãovastos, ainda há necessidade de ampliar os estudos sobre os fatores que afetam a satisfação com o trabalho na área de vendas.

Um campo de estudo que requer pesquisas é a satisfação de vendedores com o trabalho em empresas PME (Pequenas e Médias Empresas), que no Brasil representam 99\% do total de empresas e geram cerca de 15 milhões de empregos (DIEESE, 2010). Em vista da necessidade de ampliar os estudos e de conhecer o que afeta a satisfação com o trabalho na área de vendas e em empresas PME, afinal os vendedores são os responsáveis por gerar o faturamento destas, esse estudo tem como problema de pesquisa a seguinte questão: as atitudes dos chefes e dos clientes afetam a satisfação dos vendedores com o trabalho em empresas PME? A fim de responder a esta questão, essa pesquisa tem o objetivo de verificar se as atitudes dos chefes e dos clientes afetam a satisfação de vendedores com o trabalho em PME brasileiras.

Esse estudo contribui para o desenvolvimento da pesquisa acadêmica pelo fato de abordar a satisfação de vendedores com o trabalho. Entende-se como sendo algo relevante realizar mais pesquisas de satisfação de vendedores com o trabalho, visto que os vendedores são funcionários essenciais para a sobrevivência das empresas (Nonis \& Erdem, 1997; Valentine, 2009). Outra contribuição dessa pesquisa é o fato dela utilizar a escala INDSALES para mensurar a satisfação de vendedores com o trabalho, que é uma escala que capta mais dimensões do que as outras escalas, além de ter sidoprojetada especificamente para uso em ambiente de vendas (Rutherford et al.,2009). Além de utilizar a INDSALES, esse estudo verifica a participação de "dois personagens muito importantes na satisfação do vendedor com o trabalho, os chefes e os clientes" (Nonis \& Erdem, 1997, p.37).

As informações e os dados gerados nessa pesquisa podem ser utilizados de forma gerencial pelas empresas PME que, de posse das informações apresentadas, podem colocar em prática ações que contribuam para a satisfação no trabalho dos seus vendedores.

\section{Referencial Teórico}

\subsection{O Trabalho em Vendas}

Criar um ambiente que promova grande desempenho do vendedor deve ser o objetivo do gerenciamento de vendas, pois os vendedores são profissionais vitais para o sucesso das organizações. Eles precisam ser dotados de competências em vendas, conhecerem bem o produto ou serviço que vendem, possuirem habilidades que auxiliem os clientes a tomarem decisões e ter visão de futuro para enfrentar as adversidades do ambiente externo (Bartkus, Peterson, \& Bellenger, 1989; Mackenzie, Podsakoff, \& Rich, 2001; Shoemaker, 2001).

O vendedor é um elo entre a demanda do cliente e a proposta ofertada pela empresa. Ele pode ser considerado a chave em torno das vendas e da rentabilidade de qualquer negócio. Vale ressaltar que os profissionais de vendas experimentam mais estresse por causa da função se comparado com a maioria de outras profissões, além do que, também são mais propensos a enfrentar demandas emocionais pesadas (Amyx \& Bhuian, 2009; Mackenzie; Podsakoff \& Rich, 2001; Punwatkar \& Verghese, 2014).

São profissionais que levam em conta não só os seus próprios interesses, mas também os de outros, por isso, tendem a ganhar a confiança de outras pessoas com maior facilidade e a construir melhores relações sociais com os colegas de trabalho, clientes e com o próprio chefe (Erevelles \& 
Fukawa, 2013; Stan, Evans, Arnold, \& Mcamis, 2012; Yang, et al., 2013).Os vendedores processam, interiorizam e gerenciam cargas cada vez maiores de informações e precisam ser pessoas capazes de atender a clientes de diferentes crenças e necessidades (Amyx \& Bhuian, 2009; Spiro\&Weitz, 1990).

Diante de tantas mudanças e ambientes cada vez mais dinâmicos, é exigido dos vendedores que eles tenham um alto desempenho, que saibam equilibrar a necessidade de tomar decisões rápidas e a necessidade de considerar cuidadosamente as consequências de planos de ação e a resolução eficaz de conflitos. Vendedores que partilham informações entre si e com os seus chefes são mais conscientes de suas funções em uma organização e tendem a responder às mudanças competitivas e de mercado com mais rapidez (Slater \& Narver, 1995; Stan et al.,2012).

Para ter um melhor desempenho em vendas, o vendedor precisa estar motivado e satisfeito com o trabalho. A motivação e o desempenho dos vendedores precisam ser do interesse dos chefes das organizações, pois evita dispensar funcionários e também o gasto em recrutar novos vendedores. Os vendedores devem operar em estreita colaboração com um conjunto diferente de parceiros (Jones, Brown, Zoltners, \&Weitz, 2005; Mcneilly \& Goldsmith, 1991; Mackenzie; Podsakoff \& Rich, 2001).

Vendedores fortemente comprometidos preferem trabalhar em empresas que têm valores e objetivos bem definidos. O senso de propósito de cada um pode ser fomentado por uma liderança de forma que os objetivos e as aspirações de todos se tornem um só (Mackenzie, Podsakoff, \& Rich, 2001; Mcneilly \& Goldsmith, 1991; Mulki, Jaramillo, \& Locander, 2006).

Fornecer apoio individualizado ou em grupo pode ser importante em um contexto de vendas, auxiliando a reduzir o estresse e o esgotamento dos empregados, visto que o apoio profissional e emocional dos chefes desempenham um papel no estabelecimento de valores fundamentais que orientam o comportamento dos funcionários, mesmo quando o líder não está presente (Mackenzie, Podsakoff \& Rich, 2001).

Os gerentes de vendas, ao chefiar os seus vendedores, podem ser capazes de melhorar a sua eficácia substancialmente, prestando mais atenção ao seu próprio comportamento no trabalho. Os vendedores geralmente esperam que seus chefes forneçam feedbacks de preferência positivos, principalmente quando eles executam as suas tarefas bem ou acima das expectativas. Os feedbacks positivos podem gerar "sentimentos de sucesso" nos vendedores (Erevelles \& Fukawa, 2013; Goebel, Deeter-Schmelz, \& Kennedy, 2013; Mackenzie, Podsakoff \& Rich, 2001).

A condução realizada pelos chefes e a melhoria nas condições de trabalho dos vendedores pode aumentar não só a motivação e o desempenho, mas também a satisfação com o trabalho, o que consequentemente pode melhorar a qualidade do profissional (Kantak, Futrell, \& Sager, 1992). No entanto, é necessário que os chefes saibam dosar o apoio oferecido aos vendedores, para que eles não se tornem dependentes dos recursos externos e faça menos uso de suas próprias habilidades (Stan et al., 2012).

Os recursos externos têm sido consistentemente identificados como determinantes para um melhor desempenho no trabalho e os recursos internos dos vendedores são representados por seus conhecimentos, habilidades e também por suas atitudes, como a forte orientação para o cliente ou uma crença elevada na capacidade de realizar um trabalho. Os vendedores devem ter acesso às informações que fazem parte dos recursos internos e externos, a fim de que as negociações com os clientes tenham sucesso. Os vendedores devem manter um equilíbrio entre os interesses da organização em que trabalham e os interesses do cliente (Spiro \&Weitz, 1990; Stan et al.,2012).

As organizações e os vendedores precisam estabelecer uma relação estreita e perene com os clientes, para que se estabeleça a fidelidade entre eles e a empresa. Para alcançar a fidelidade de seus clientes, a empresa tem que ter em mente que nenhum benefício está a salvo de ser correspondido ou ultrapassado pelos concorrentes (Slater \& Narver, 1995). A fidelidade acontece a partir do momento que há confiança entre o vendedor e o cliente, haja vista que a confiança aumenta a satisfação do comprador e as intenções de compra (Erevelles \& Fukawa, 2013; Stan et al., 2012). É de grande importância que os vendedores sejam justos, honestos e transparentes nas suas relações com os clientes (Punwatkar \&Verghese, 2014).

Vendedores satisfeitos com o trabalho podem ter uma tendência não só a aproximar-se mais dos clientes, mas também ter melhor desempenho e uma maior facilidade em atendê-los melhor (Erevelles \& Fukawa, 2013). Para isso, investir na capacitação psicológica e profissional dos vendedores é uma maneira de influenciar positivamente não só na satisfação dos seus clientes, mas na sua própria satisfação com o trabalho (Stan et al., 2012). 


\subsection{Satisfação com o Trabalho em Vendas}

A satisfação com o trabalho tem sido definida como um estado emocional agradável ou positivo resultante da avaliação de um posto de trabalho ou experiências de trabalho (Locke, 1976). Ela reflete o quão bem as pessoas gostam ou não do trabalho (Spector, 1997). As pessoas geralmente se tornam satisfeitas quando elas gostam e valorizam o seu trabalho e se sentem valorizadas no ambiente de trabalho (Nonis \& Erdem, 1997). A satisfação com o trabalho merece ser estudada em profundidade por estar associada a muitos aspectos não só da vida profissional, mas também em aspectos da vida pessoal (Kantak, Futrell, \& Sager, 1992; Jones, Brown, Zoltners, \&Weitz, 2005).

É relevante no estudo da satisfação com o trabalho que estudiosos pesquisem, analisem e cheguem a uma compreensão completa de atitudes do trabalho e dos elementos constituintes de uma ocupação (Stan et. al., 2012). Existem as dimensões básicas do trabalho que podem ser identificadas em qualquer ocupação, mas vale ressaltar que um trabalho não é uma entidade, mas uma inter-relação complexa de tarefas, papéis, responsabilidades, interações, incentivos e recompensas, que são características de cada profissão (Koppitsch, Folkes, Macinnis, \& Porath, 2013; Locke, 1976).

A satisfação com o trabalho dos vendedores deriva da análise entre a satisfação e as diferentes dimensões do trabalho, que influenciam não só a motivação e o desempenho, mas também outros aspectos como, por exemplo, o comportamento do vendedor (Futrell, 1979; Stan et al.,2012; Koppitsch et. al., 2013). A satisfação do vendedor com o trabalho leva ao comprometimento organizacional (Mulki, Jaramillo, \& Locander, 2006).

Um importante estudo sobre a satisfação de vendedores com o trabalho foi publicado por Churchill, Ford e Walker (1974), que desenvolveram a escala INDSALES, a mais completa das escalas, com 95 itens para mensuração da satisfação de vendedores com o trabalho (Nonis \& Erdem, 1997).

As escalas de medição de satisfação com o trabalho, entre elas a INDSALES, foram criadas para permitir aos pesquisadores obterem uma avaliação mais precisa e completa do construto (Rutherford et al., 2009). O estudo de Churchill, Ford e Walker (1974) apresenta uma medida da satisfação de vendedores industriais com o trabalho. Por meio da escala, eles constataram que a satisfação de vendedores com o trabalho é afetada por sete dimensões: o próprio trabalho, colegas de trabalho, supervisor (chefe), salário, promoção, política da empresa e clientes. Também observaram que $40 \%$ da variação na satisfação total do trabalho entre os vendedores é explicada pelas políticas e práticas empresariais, bem como o comportamento do chefe (Mulki, Jaramillo, \& Locander, 2006).

Estudos posteriores ao de Churchill Jr, Ford e Walker Jr (1974), como Comer, Machleit e Lagace (1989), Futrell (1979), Nonis e Erdem (1997), mediram a satisfação de vendedores com o trabalho por meio da INDSALES. Eles fizeram acréscimos no estudo iniciado por Churchill, Ford e Walker (1974), mas não realizaram um trabalho similar, por não usarem a versão tradicional da escala e por terem escolhido uma amostra específica para estudo. Inclusive, alguns usaram a versão reduzida da INDSALES desenvolvida e validada por Childers e Ferrell (1979).

\subsection{As Dimensões da Satisfação do Vendedor com o Trabalho}

A INDSALES foi desenvolvida na pesquisa realizada por Churchill Jr, Ford e Walker Jr (1974), que identificaram as sete dimensões do construto satisfação no trabalho de vendedores, sendo elas: (1) o trabalho em si; (2) colegas de trabalho; (3) supervisão (chefe); (4) política da empresa e suporte; (5) salário e benefícios da empresa; (6) promoção e progresso (oportunidades) na carreira; e (7) os clientes (Churchill Jr; Ford \& Walker Jr, 1974).

A primeira dimensão, o trabalho em si, corresponde ao próprio trabalho realizado pelo vendedor. A segunda são os colegas de trabalho, isto é, aqueles funcionários que dividem tarefas dentro da mesma empresa. A terceira, supervisão, é representada pelo gerente ou chefe a quem o vendedor é subordinado. A quarta, política da empresa e suporte, é referente à administração realizada na empresa, no gerenciamento de tarefas e no suporte oferecido aos funcionários pela empresa. A quinta, salário e benefícios da empresa, é relacionada à remuneração e aos benefícios que a empresa oferece aos seus colaboradores. A sexta está ligada às promoções na carreira dentro da empresa em que trabalha. E, por fim, a sétima dimensão é ligada à visão que o funcionário tem dos clientes que atende (Churchill, Ford, \& Walker Jr, 1974). 


\begin{tabular}{|c|c|c|}
\hline Dimensões & $\begin{array}{l}\text { Total de } \\
\text { itens }\end{array}$ & Itens da Escala \\
\hline \multirow{10}{*}{ Chefe } & \multirow{10}{*}{10} & 1. Meu chefe é discreto \\
\hline & & 2. Meu chefe é uma pessoa atualizada \\
\hline & & 3. Meu chefe realmente tenta pegar nossas ideias sobre as coisas e colocar em prática \\
\hline & & $\begin{array}{l}\text { 4. Meu chefe faz um bom trabalho ao ajudar as pessoas de vendas a desenvolverem o seu } \\
\text { próprio potencial }\end{array}$ \\
\hline & & 5. Meu chefe sempre foi justo nas relações comigo \\
\hline & & 6. Meu chefe sabe desenvolver suas funções muito bem \\
\hline & & 7. Meu chefe faz a força de vendas trabalhar em conjunto, como uma equipe \\
\hline & & 8. Meu chefe nos dá crédito e louvor pelo trabalho bem feito \\
\hline & & 9. Meu chefe faz jus às suas promessas \\
\hline & & 10. Meu chefe sabe muito pouco sobre seu trabalho \\
\hline \multirow{9}{*}{ Trabalho } & \multirow{9}{*}{9} & 11. Me sinto realizado (a) profissionalmente com o meu trabalho. \\
\hline & & 12. O trabalho é muitas vezes maçante e monótono \\
\hline & & 13. Meu trabalho é emocionante \\
\hline & & 14. Meu trabalho não me motiva \\
\hline & & 15. Meu trabalho está me satisfazendo \\
\hline & & 16. Eu estou realmente fazendo algo de valor no meu trabalho \\
\hline & & 17. Meu trabalho é um desafio \\
\hline & & 18. Meu trabalho é uma rotina \\
\hline & & 19. Meu trabalho é interessante \\
\hline \multirow{11}{*}{$\begin{array}{l}\text { Política } \\
\text { empresa } \\
\text { suporte }\end{array}$} & \multirow{11}{*}{11} & 20. A gestão da empresa tem uma visão de futuro. \\
\hline & & 21. A gestão de topo (presidência e os diretores) realmente conhece o meu trabalho \\
\hline & & 22. Esta empresa opera de forma eficiente e sem problemas \\
\hline & & $\begin{array}{l}\text { 23. Os programas formais de reconhecimento nesta empresa não me dão muito incentivo } \\
\text { para trabalhar mais }\end{array}$ \\
\hline & & $\begin{array}{l}\text { 24. Estou satisfeito com a forma como os nossos programas de reconhecimento formais } \\
\text { são administrados }\end{array}$ \\
\hline & & 25. Vendedores da empresa recebem um bom apoio da supervisão e/ou diretoria \\
\hline & & 26. A gestão ignora nossas sugestões e reclamações \\
\hline & & $\begin{array}{l}\text { 27. Programas formais de reconhecimento na empresa são comparados favoravelmente } \\
\text { com os de outras empresas }\end{array}$ \\
\hline & & 28. Eu não recebo o reconhecimento formal suficiente para o trabalho que eu faço \\
\hline & & 29. Prêmios de reconhecimento são baseados na capacidade de vendas \\
\hline & & 30. Tenho confiança na justiça e honestidade da gestão \\
\hline \multirow{7}{*}{ Promoção } & \multirow{7}{*}{7} & 31. A empresa tem uma política de promoção injusta \\
\hline & & 32. Minhas oportunidades de progresso são limitadas \\
\hline & & 33. Há uma abundância de bons empregos aqui para aqueles que querem ficar à frente \\
\hline & & 34. Este é um trabalho sem fim \\
\hline & & 35. Promoção é baseada na capacidade de vendas \\
\hline & & 36. Minhas oportunidades de progresso são razoáveis \\
\hline & & 37. Eu tenho uma boa chance de ser promovido (a) \\
\hline \multirow{8}{*}{ Salário } & \multirow{8}{*}{8} & $\begin{array}{l}\text { 38. Meu salário é alto em comparação com o de outros que tentam conseguir empregos } \\
\text { similares }\end{array}$ \\
\hline & & $\begin{array}{l}\text { 39. Meu salário é baixo em comparação com de outros que tentam conseguir empregos } \\
\text { similares }\end{array}$ \\
\hline & & 40. Na minha opinião, o salário aqui é menor do que em outras empresas \\
\hline & & 41. Eu sou muito bem pago \\
\hline & & 42. Minha renda permite que eu tenha luxos. \\
\hline & & 43. Sou pago o bastante em comparação com os outros empregados desta empresa \\
\hline & & 44. Minha renda é suficiente para as despesas normais \\
\hline & & 45. Sou muito mal pago para o trabalho que eu faço \\
\hline \multirow{9}{*}{$\begin{array}{l}\text { Colegas } \\
\text { trabalho }\end{array}$} & \multirow{9}{*}{9} & 46. Meus colegas de trabalho são egoístas \\
\hline & & 47. Meus colegas de trabalho são agradáveis \\
\hline & & 48. As pessoas com quem trabalho são muito amigáveis \\
\hline & & 49. Meus colegas de trabalho são leais \\
\hline & & 50. Meus colegas de trabalho são inteligentes \\
\hline & & 51. Meus colegas de trabalho são responsáveis \\
\hline & & 52. Meus colegas de trabalho me estimulam a trabalhar \\
\hline & & $\begin{array}{l}\text { 53. Meus colegas de trabalho costumam ajudar na hora em que alguém não desempenha } \\
\text { bem o seu trabalho }\end{array}$ \\
\hline & & 54. Meus colegas de trabalho não atraem clientes \\
\hline \multirow{7}{*}{ Clientes } & \multirow{7}{*}{7} & 55. Meus clientes entendem sobre o que querem comprar \\
\hline & & 56. Meus clientes estão interessados em que eu tenho a dizer \\
\hline & & 57. Meus clientes compram o que realmente dizem que vão comprar \\
\hline & & 58. Meus clientes são confiáveis \\
\hline & & 59. Meus clientes são justos \\
\hline & & 60. Meus clientes são leais \\
\hline & & 61. Meus clientes entendem o meu trabalho de vendedor \\
\hline
\end{tabular}

Figura 1 - Escala INDSALES (versão Childers e Ferrell)

Nota. Fonte: Childers e Ferrell (1979), Versão traduzida pela autora. Observação: Questão no 04 referente a dimensão Chefe foi excluída por apresentar alta correlação com os demais itens do construto 
Após a seleção dos componentes da escala, os autores construíram um questionário de 95 itens e depois de analisarem, testarem e revisarem o instrumento, usando uma amostra heterogênea de vendedores para avaliar a generalização da escala, ajustou-se a escala. Os sete componentes foram apresentados ao lado de uma Escala de Likert de cinco pontos, com possíveis respostas que iam desde "discordo totalmente" para "concordo totalmente" (Churchill, Ford, \& Walker, 1974).

A escala desenvolvida por Churchill, Ford e Walker (1974) é considerada uma das melhores escalas para mensurar a satisfação com o trabalho do vendedor, devido à abrangência dos itens de cada dimensão (Boles, et al.,2007; Nonis \& Erdem, 1997). Apesar de a INDSALES ser completa, Childers e Ferrell (1979) propuseram uma versão reduzida dessa escala com 61 itens, com o mesmo formato e mantiveram as sete dimensões propostas por Churchill, Ford e Walker (1974), ressaltando que essa redução não comprometeu a validez da escala (Comer, Machleit\&Lagace, 1989). Essa escala reduzida serviu de modelo para realização desta pesquisa (Figura 1). A redução na escala original proposta por Childers e Ferrell (1979) auxilia os pesquisadores a obterem mais respostas dos vendedores, que tendem a ficar menos cansados ao responderem um questionário menor (Comer, Machleit \& Lagace, 1989; Spagnoli, Caetano \& Santos, 2012).

Para alcançar o objetivo desse estudo, foi escolhido trabalhar com duas dimensões da escala INDSALES: os chefes e os clientes. A escolha em trabalhar com as duas dimensões foi feita devido aos seguintes fatores: trabalhar com as sete dimensões propostas pela INDSALES tornaria o questionário dessa pesquisa longo, o que poderia diminuir a probabilidade de respondentes quererem participar da pesquisa. Além disso, os chefes são os indivíduos mais importantes e influentes ao decidirem e formarem o cenário de trabalho para os vendedores e outros membros da organização (Valentine, 2009). A conduta dos chefes pode ser uma poderosa ferramenta para o fortalecimento das ações de uma organização de vendas, pois os vendedores e outros funcionários trabalham de acordo com o que chefe delega para eles. Os chefes interagem diretamente com autonomia e podem tomar medidas para garantir que os clientes sejam bem atendidos pelos vendedores (Churchill, Ford \& Walker, 1974; Valentine, 2009).

Por fim, a escolha pela dimensão Cliente é pelo fato do cliente ser um indivíduo muito importante no cotidiano dos vendedores, pois está diariamente em contato com eles e é o responsável por gerar lucro para as empresas (Boulding, Kalra, Staelin, \& Zeithaml, 1993). Os clientes normalmente têm interações pessoais com os vendedores, ao estabelecerem uma relação de confiança e fidelidade com o vendedor e também com o que estão adquirindo (Mantel, 2005). Por fim, a escala reduzida para mensurar a satisfação com o trabalho é um instrumento que tende a aumentar a qualidade de respostas, não desqualificando a escala original e permitindo tratar as variáveis em separado (Childers \& Ferrel, 1979; Comer, Machleit \& Lagace, 1989).

\section{Metodologia}

A metodologia de pesquisa utilizada nesse estudo foi de natureza descritiva e quantitativa. A partir do objetivo da pesquisa, que foi verificar se as atitudes dos chefes e dos clientes afetam a satisfação de vendedores com o trabalho em PME brasileiras, definiu-se a população do estudo, sendo composta por vendedores que se enquadram na categoria de vendedores de PME brasileiras. A escolha da população foi devido à importância dos vendedores para as organizações e o tipo de empresa foi pelo fato da maioria das empresas brasileiras se encaixarem na categoria de PME e por elas gerarem muitosempregos para a população brasileira. Não houve classificação da quantidade populacional de vendedores, ou seja, a quantidade é desconhecida. Sendo assim, a amostra utilizada no estudo foi de caráter não probabilístico por conveniência.

Para a coleta de dados foi elaborado um instrumento com base na escala INDSALES, de autoria de Childers e Ferrell (1979), respeitando as premissas com a qual foi desenvolvida a original, apenas tendo sido traduzida para a língua portuguesa e excluído o item de no4 da dimensão Chefe, por apresentar alta correlação com os demais itens do construto. A coleta de dados aconteceu a partir da aplicação do questionário no local de trabalho dos vendedores e também por e-mail e redes sociais. O questionário foi constituído por afirmações acompanhadas de uma escala de concordância, o que permitiu aos entrevistados escolherem uma opção entre as alternativas demonstradas, com perguntas e afirmações diretas. O questionário abordou 3 construtos: satisfação com o trabalho, as atitudes dos chefes e as atitudes dos clientes. Essas variáveis foram representadas por afirmações, acompanhadas de uma Escala de Likert de cinco pontos.As respostas variaram entre 1 ("Discordo totalmente") e 5 ("Concordo totalmente").

Como já comentado, para verificar se as atitudes dos chefes e dos clientes afetam a satisfação de vendedores com o trabalho em PME brasileiras, foi escolhido estudar a satisfação com o trabalho a partir de duas dimensões: chefes e clientes. Estas dimensões, de acordo com a escala INDSALES, são independentes das demais dimensões da mesma escala, conforme demonstrado por Churchill, 
Ford e Walker (1974).O questionário foi desenvolvido com 21 itens, baseado nas duas dimensões, chefe e cliente, da versão reduzida da escala INDSALES proposta por Childers e Ferrell (1979) e apresentados anteriormente na Figura 1. As quatro primeiras perguntas foram para caracterizar a população estudada e a primeira afirmação foi relacionada a satisfação com o trabalho (variável dependente). Além disso, nove afirmações abordaram a percepção dos vendedores a respeito das atitudes de seus chefes e sete afirmações abordaram a percepção dos vendedores a respeito das atitudes de seus clientes.

Para validar o questionário, foi realizado um pré-teste com uma amostra de 16 vendedores que fazem parte do público-alvo desse estudo. Após a validação, a pesquisa foi realizada com vendedores escolhidos por acessibilidade, tendo sido utilizada a ferramenta online Google Docs, aplicando-se diretamente aos vendedores por meio de um aparelho Tablet ligado à Internet. A aplicação ocorreu dentro do local de trabalho do vendedor, que por livre escolha aceitou responder ao questionário em um momento em que não estivesse atendendo a um cliente. O local de aplicação do questionário foi em lojas de pequeno e médio porte de dois shoppings, escolhidas por conveniência. O questionário também foi enviado por via eletrônica, e-mail e rede social. Ao todo, obteve-se 255 respostas, sem nenhum descarte, pois não houve nenhuma pesquisa incompleta.

Para avaliar os resultados, foram utilizados métodos estatísticos. Primeiramente, a amostra foi caracterizada a partir dos dados obtidos, que auxiliaram a resumir o perfil geral dos vendedores. Ademais, isto também ajudou a verificar se todos os respondentes estavam dentro do público-alvo da pesquisa. Em segundo, visando o objetivo proposto, foram analisadas as estatísticas descritivas, observando a média e o desvio padrão de cada variável medida. Para alcançar o objetivo desse estudo, foi utilizada uma regressão. A regressão teve como variável dependente a satisfação com o trabalho, em queos vendedores indicaram no questionário em uma escala de 1 (totalmente insatisfeito) a 5 (totalmente satisfeito) se eles estão satisfeitos com o seu trabalho. Nessa regressão, verificou-se se que a satisfação com o trabalho estava associada às variáveis independentes (variáveis que medem a percepção dos vendedores sobre as atitudes dos chefes e clientes).

\section{Análise e Discussão dos Resultados}

\subsection{Caracterização da Amostra}

A fim de identificar as informações sobre os respondentes, o questionário apurou, por meio de quatro perguntas, o gênero, a faixa etária, o nível de escolaridade e o setor de vendas em que o respondente trabalha. Os resultados foram apresentados na Tabela 1. De acordo com a Tabela 1 , percebeu-se que a maioria dos vendedores respondentes é do gênero feminino (67\%) e está na faixa etária dos 25 a 32 anos de idade (44\%), porém notou-se que os vendedores na faixa entre 17 a 24 anos de idade (29\%) também possuem expressiva representatividade. Quanto ao nível de escolaridade, os dados demonstraram que a maioria dos respondentes possui ensino médio completo (58\%), o que representa mais da metade dos vendedores que participaram da pesquisa. Em relação ao setor de vendas em que trabalham a maioria dos vendedores, $80 \%$, trabalham no setor varejista ou comércio, seguido pelo setor farmacêutico (7\%) e outros (7\%).

Tabela 1:

Resumo da caracterização da amostra

\begin{tabular}{|c|l|c|}
\hline \multicolumn{2}{|c|}{ CARACTERIZAÇÃO DA AMOSTRA } \\
\hline \multirow{4}{*}{ GÊNERO } & Feminino & $67 \%$ \\
\cline { 2 - 3 } & Masculino & $33 \%$ \\
\hline \multirow{4}{*}{ FAIXA ETARIA } & 17 a 24 anos & $29 \%$ \\
\cline { 2 - 3 } & 25 a 32 anos & $44 \%$ \\
\cline { 2 - 3 } & 33 a 40 anos & $17 \%$ \\
\cline { 2 - 3 } & 41 a 48 anos & $8 \%$ \\
\cline { 2 - 3 } & Acima de 48 anos & $2 \%$ \\
\hline \multirow{4}{*}{ NIVEL DE ESCOLARIDADE } & Fundamental completo & $1 \%$ \\
\cline { 2 - 3 } & Médio incompleto & $4 \%$ \\
\cline { 2 - 3 } & Médio completo & $58 \%$ \\
\cline { 2 - 3 } & Superior incompleto & $27 \%$ \\
\cline { 2 - 3 } & Superior completo & $7 \%$ \\
\cline { 2 - 3 } & Pós-superior incompleto & $1 \%$ \\
\cline { 2 - 3 } & Pós-superior completo & $2 \%$ \\
\hline & Atacadista & $80 \%$ \\
\cline { 2 - 3 } & Varejista & $7 \%$ \\
\cline { 2 - 3 } & Farmacêutico & $7 \%$ \\
\cline { 2 - 3 } & Telefonia/Internet/Tecnologia & $7 \%$ \\
\cline { 2 - 3 } & Outros & \\
\hline
\end{tabular}

Fonte: Dados da pesquisa. 
Por fim, essa primeira parte da análise dos dados teve a função de apontar se a amostra se enquadra no perfil do público-alvo do estudo, de maneira a validar a amostra. Observando a Tabela 1 , assume-se que a amostra está de acordo com os objetivos do estudo, visto que não houve tendências e vieses que pudessem invalidar o estudo. Portanto, percebe-se que a amostra é de caráter heterogêneo e representa o típico vendedor de PMEs, com as seguintes características: jovem, com pouca escolaridade, majoritariamente feminino e atua profissionalmente no setor de varejo, o que permite uma análise genérica.

\subsection{Estatística Descritiva}

Foi realizada uma análise descritiva de cada uma das afirmações, de maneira que fosse possível observar a média e o desvio padrão (DP) de cada uma. Para facilitar a compreensão e a interpretação dos dados, cada variável foi transformada em um código (Hair, Babin, Money, \& Samouel, 2005) apresentados na Tabela 2. A variável Y (satisfação com o trabalho) foi a variável dependente. Já as que começam com o código $\mathrm{CH}$ são as variáveis independentes relacionadas à percepção que os vendedores têm das atitudes de seus chefes e as que iniciam com o código CL são as variáveis independentes relacionadas à percepção que eles possuem das atitudes dos seus clientes.

Ao observar a Tabela 2, foi possível perceber que a maioria das variáveis obteve médias acima de 3. Apenas uma variável, a $\mathrm{CH} 9$ (baixo conhecimento), obteve média abaixo deste valor. A estatística descritiva também demonstra que 8 variáveis possuem médias acima de 4: a variável dependente $Y$ (satisfação com o trabalho), a $\mathrm{CH} 1$ (comportamento), a $\mathrm{CH} 2$ (atualização), a $\mathrm{CH} 4$ (justo com o vendedor), a $\mathrm{CH} 5$ (desenvolvimento de funções), a $\mathrm{CH} 8$ (comprometimento), a CL2 (interesse) e a CL7 (compreensão).

A variável dependente $Y$ (satisfação com o trabalho) questionou a satisfação do vendedor com o seu trabalho. Essa pergunta teve a intenção de avaliar se os vendedores possuem sentimentos positivos em relação ao trabalho e se as experiências que eles tiveram e ainda têm no emprego os satisfazem. Por meio da escala, os vendedores avaliaram o quanto eles estavam satisfeitos com o trabalho.

Tabela 2:

Estatística descritiva

\begin{tabular}{|c|l|c|c|}
\hline CÓDIGO & \multicolumn{1}{|c|}{ VARIÁVEL/ATRIBUTO } & MÉDIA & $\begin{array}{c}\text { DESVIO } \\
\text { PADRÃO }\end{array}$ \\
\hline Y & SATISFAÇÃO COM O TRABALHO & 4,02 & 0,71 \\
\hline CH1 & COMPORTAMENTO & 4,42 & 0,79 \\
\hline CH2 & ATUALIZAÇAOO & 4,17 & 0,71 \\
\hline CH3 & COLOCA EM PRÁTICA AS IDEIAS DOS VENDEDORES & 3,76 & 0,78 \\
\hline CH4 & JUSTO COM O VENDEDOR & 4,31 & 0,70 \\
\hline CH5 & DESENVOLVIMENTO DE FUNÇÖES & 4,05 & 0,69 \\
\hline CH6 & FORÇA DE VENDAS & 3,93 & 0,71 \\
\hline CH7 & RECONHECIMENTO & 3,93 & 0,69 \\
\hline CH8 & COMPROMETIMENTO & 4,27 & 0,82 \\
\hline CH9 & BAIXO CONHECIMENTO & 2,04 & 1,10 \\
\hline CL1 & ENTENDIMENTO & 3,87 & 0,86 \\
\hline CL2 & INTERESSE & 4,20 & 0,70 \\
\hline CL3 & COMPROMETIMENTO & 3,24 & 0,77 \\
\hline CL4 & CONFIANÇA & 3,41 & 0,78 \\
\hline CL5 & CORRETOS & 3,76 & 0,78 \\
\hline CL6 & LEALDADE & 3,53 & 0,77 \\
\hline CL7 & COMPREENSÃO & 4,10 & 1,00 \\
\hline
\end{tabular}

Fonte: Dados da pesquisa.

A A estatística descritiva apontou que a variável Y obteve a média de 4,02 e o DP (Desvio Padrão) de 0,71. A alta média de $Y$ indica que a maioria dos vendedores pesquisados, $76,6 \%$, está satisfeita com o trabalho. Vale ressaltar que, mesmo a maioria estando satisfeita com o trabalho, a variável apresentou uma quantidade expressiva de $23,4 \%$ de vendedores que avaliaram medianamente a satisfação com o trabalho. O DP indica que a variação entre o número de pessoas insatisfeitas e satisfeitas com o trabalho não é grande. As variáveis independentes relacionadas à percepção que os vendedores possuem das atitudes dos seus chefes são $\mathrm{CH} 1$ (comportamento); $\mathrm{CH} 2$ (atualização); $\mathrm{CH} 3$ (coloca em prática as ideias dos vendedores); $\mathrm{CH} 4$ (justo com o vendedor); $\mathrm{CH} 5$ (desenvolvimento de funções); $\mathrm{CH} 6$ (força de vendas); $\mathrm{CH} 7$ (reconhecimento); $\mathrm{CH} 8$ (comprometimento); e $\mathrm{CH} 9$ (baixo conhecimento). 
A variável $\mathrm{CH} 1$ (comportamento) teve a intenção de saber dos vendedores se, na visão deles, seu chefe se comporta adequadamente no ambiente de trabalho. De acordo com a estatística, a variável $\mathrm{CH} 1$ apresentou a média de 4,42 e o DP de 0,79. A alta média indica que a maioria dos vendedores (88\%) concordou que os chefes sabem se comportar no trabalho. O DP indicou que poucos vendedores discordaram da afirmação. A CH2 (atualização), meu chefe é uma pessoa atualizada, apresentou a média de 4,17 e o DP de 0,71. A média informa que a maioria dos respondentes, $85 \%$, concordou que o chefe é uma pessoa atualizada. O DP apontou que um número pequeno de pessoas discordou da afirmação.

A variável $\mathrm{CH} 3$ (coloca em prática as ideias dos vendedores) teve a intenção de saber dos vendedores se o seu chefe tenta colocar em prática as ideias que os vendedores dão no ambiente de trabalho. Estatisticamente, a $\mathrm{CH} 3$ apresentou a média de 3,76 e o DP de 0,78, o que indicou que a maioria (68\%) dos vendedores concordou com a afirmação, mas uma parcela expressiva de $27 \%$ respondeu que os chefes são indiferentes. A CH4 (justo com o vendedor) verificou o fato de o chefe ser justo no trabalho com o vendedor. A variável apresentou a alta média de 4,31 e o DP de 0,70, apontando que a maioria (90\%) dos pesquisados concordaram com a afirmação, indicando alto percentual de vendedores que consideram que poucos sofreram com alguma injustiça por parte do chefe. O DP apontou pouca discordância nesta afirmação.

O desenvolvimento de funções ( $\mathrm{CH} 5)$ teve a intenção de os vendedores avaliarem se os chefes sabem desenvolver muito bem as suas funções. Com uma média de 4,05 e um DP de 0,69, a maioria $(85 \%)$ dos vendedores respondeu que concorda que o seu chefe sabe desenvolver as suas funções muito bem. A CH6 (força de vendas) verificou se na percepção dos vendedores, o chefe faz com que a força de vendas trabalhe em equipe, de forma integrada. A estatística apontou para a CH6 a média de 3,93 e o DP de 0,71 . Sendo assim, a maioria (75\%) dos vendedores concordou que o chefe faz a força de vendas trabalhar em equipe, mas uma fatia expressiva de $22 \%$ dos respondentes afirmou que o esforço do chefe para que a equipe trabalhe integrada é mediano.

A variável $\mathrm{CH} 7$ (reconhecimento) verificou se o chefe dá crédito e louvor ao vendedor pelo trabalho bem feito. Tal afirmação obteve média de 3,93 e DP de 0,69. Por meio desses dados, verificou-se que a maioria (78\%) dos vendedores concordou com a afirmação, sendo que $19 \%$ afirmaram que o reconhecimento por parte do chefe é mediano. O comprometimento do chefe em cumprir com as suas promessas, representado pela variável CH8, obteve média de 4,27 e DP de 0,82 . A maioria (85\%) dos vendedores concordou que o seu chefe faz jus às suas promessas, com rara discordância. A variável $\mathrm{CH} 9$ (baixo conhecimento) verificou se o chefe sabe muito pouco sobre - trabalho dele. Apesar de possuir a menor média $(2,04)$ do grupo geral das variáveis independentes, a CH9 em contrapartida possui o maior DP, no valor de 1,10. A média indicou que a maioria (79\%) dos vendedores discordou da afirmação, ou seja, eles acreditaram que seus chefes sabem muito sobre o próprio trabalho. Quanto ao DP, é interessante notar que a variação entre as pessoas que discordaram (79\%) e as pessoas que concordaram não é expressiva, pois $13 \%$ dos vendedores concordaram com a afirmação.

Os dados referentes às variáveis $\mathrm{CH} 2, \mathrm{CH} 4, \mathrm{CH} 5, \mathrm{CH} 6, \mathrm{CH} 7$ e $\mathrm{CH} 8$, que apresentaram desvios padrão menores, confirmaram os estudos de Slater e Narver (1995) e de Rutherford et al. (2009), que afirmam que os chefes são pessoas que necessitam estar atualizados quanto à sua profissão e estar próximos dos vendedores, agindo como seus líderes e motivando-os. Além disso, é possível constatar, por meio das médias das variáveis $\mathrm{CH} 3, \mathrm{CH} 4, \mathrm{CH} 7$, e $\mathrm{CH}$, que os resultados obtidos aqui são coerentes com os estudos de Slater e Narver (1995), Mackenzie, Podsakoff e Rich (2001) e Stan et al. (2012). Sendo assim, pode-se afirmar que, na visão dos respondentes, a maioria dos chefes coloca em prática as ideias que os vendedores dão no trabalho, são justos com os vendedores, dão crédito e louvor pelo trabalho bem feito e fazem jus às promessas feitas aos funcionários.

A percepção que os vendedores possuem dos clientes é representada pelas variáveis independentes CL1 (entendimento); CL2 (interesse); CL3 (comprometimento); CL4 (confiança); CL5 (corretos); CL6 (lealdade); e CL7 (compreensão). A variável CL1 (entendimento) obteve média de 3,87 e DP de 0,86 . Esses dados demonstraram que a maioria dos vendedores $(72 \%)$ concordou que os clientes entendem sobre o que querem comprar, mas, por outro lado, $22 \%$ dos vendedores discordaram da afirmação. A variável CL2 (interesse) verificou o interesse que os clientes têm no que o vendedor tem a dizer. Com a alta média de 4,20 e o DP de 0,70, a variável CL2 mostrou que $89 \%$ dos vendedores pesquisados concordaram com a afirmação, com pouca discordância. Esse dado confirmou os estudos de Erevelles e Fukawa (2013), Stan et al. (2012), Amyx e Bhuian (2009) e Jones et al. (1995), que discorreram sobre assuntos como a importância dos vendedores e da presença deles para auxiliar os clientes nas compras.

A variável CL3 (comprometimento) é a variável relacionada ao cliente que apresentou a menor média $(3,24)$ e o DP de 0,77 . A maioria $(57 \%)$ dos vendedores respondeu que não concordam e nem discordam que os clientes compram o que realmente dizem que vão comprar. Já a confiança que os 
vendedores têm acerca dos clientes, variável CL4, apresentou média de 3,41 e DP de 0,78. Os dados demonstraram que os vendedores são indecisos com relação a esse item, visto que $49 \%$ dos respondentes não concordaram que eles são confiáveis ou não confiáveis. Já $44 \%$ dos vendedores concordaram que os clientes são pessoas confiáveis. A variável CL5 (corretos) obteve média de 3,76 e DP de 0,78 , o que demonstrou que a maioria dos vendedores $(72 \%)$ concordou que os clientes são pessoas justas, o que se entende por pessoas que reconhecem o direito de outra pessoa, não somente o dela próprio, sendo corretos com os outros. Vale citar que a expressiva fatia de $23 \%$ dos vendedores afirmou que o senso de justiça dos clientes é de nível médio.

A CL6 (lealdade) apresentou média de 3,53 e um DP de 0,77. Os dados mostram que a maioria $(56 \%)$ dos respondentes concordou que os seus clientes são leais, mas, em contrapartida, $36 \%$ responderam que os clientes são inconstantes. Esses $36 \%$ dos clientes inconstantes em relação à lealdade pode estar ligado à quantidade de oferta de diferentes produtos ou serviços iguais e similares no mercado ou por outros motivos que podem ser investigados em pesquisas futuras. A última variável independente, CL7 (compreensão) obteve média alta de 4,10 e foi a variável relacionada ao cliente que apresentou o maior DP $(1,00)$. Os dados indicaram que a CL7 possui pouca variação entre os extremos do discordo totalmente e o concordo totalmente, pois $76 \%$ dos vendedores concordaram que os clientes entendem o seu trabalho e apenas $5 \%$ discordaram da afirmação.

Por fim, diante dos resultados da estatística descritiva apresentada na Tabela 2 e dos resultados aqui analisados, foi possível verificar por meio das médias e dos desvios padrão que a satisfação dos vendedores com o trabalho, segundo eles mesmos, é mais afetada pelos chefes do que pelos clientes, coerente com os estudos de Churchill, Ford e Walker (1974), Kantak, Futrell e Sager (1992), Slater e Narver (1995) e Mackenzie, Podsakoff e Rich (2001) e Stan et al. (2012).

\subsection{Regressão Linear Múltipla}

Com o objetivo de verificar se as atitudes dos chefes e dos clientes afetam a satisfação de vendedores com o trabalho em PME brasileiras, a regressão realizada teve como variável dependente a satisfação com o trabalho $(Y)$. As variáveis independentes foram as atitudes de chefes e clientes. Os resultados são apresentados na Tabela 3 e 4.

Tabela 3:

Modelo obtido na regressão

\begin{tabular}{|c|c|c|c|c|c|c|c|c|c|c|}
\hline \multicolumn{11}{|c|}{ Resumo do Modelo } \\
\hline \multirow[b]{2}{*}{ Modelo } & \multirow[b]{2}{*}{$\mathrm{R}$} & \multirow[b]{2}{*}{$\mathrm{R}^{2}$} & \multirow{2}{*}{$\begin{array}{c}\mathrm{R}^{2} \\
\text { ajustado }\end{array}$} & \multirow{2}{*}{$\begin{array}{c}\text { Estimativa } \\
\text { do Desvio } \\
\text { Padrão }\end{array}$} & \multicolumn{5}{|c|}{ Estatísticas modificadas } & \multirow{2}{*}{$\begin{array}{l}\text { Durbin- } \\
\text { Watson }\end{array}$} \\
\hline & & & & & $\begin{array}{c}\mathrm{R}^{2} \\
\text { modificado }\end{array}$ & $\begin{array}{c}\mathrm{F} \\
\text { modificado }\end{array}$ & df1 & $d f 2$ & $\begin{array}{c}\text { Sig. F } \\
\text { modificada }\end{array}$ & \\
\hline 4 &, $486^{d}$ & ,237 &, 224 &, 62254 &, 012 & 3,989 & 1 & 250 &, 047 & 1,750 \\
\hline
\end{tabular}

Nota, Fonte: Dados da Pesquisa

Obs: Método de estimação: Stepwise

Testes de validez:

ANOVA: significativo

Teste de Aleatoriedade: Suporta a hipótese de Aleatoriedade

Teste de Aderência Kolmogorov-Smirnov: Suporta hipótese de Aderência a distribuição normal

Teste de Homocedasticidade: Suporta a hipótese de homocedasticidade

Validez de construtos:

Alfa de Cronbach para a dimensão Chefe: 0,88

Alfa de Cronbach para a dimensão Cliente: 0,81

Observando-se as Tabelas 3 e 4, percebe-se que o R2 ajustado, que demonstra quanto as variáveis independentes significativas ( $\mathrm{CH} 3, \mathrm{CH} 4, \mathrm{CL} 4$ e CL7) explicam a variação da variável dependente $Y$ (satisfação com o trabalho), ficou em 22,4\%. As variáveis independentes apresentaram índices de significância abaixo do valor de 0,05, isto é, as variáveis independentes são significativas a $5 \%$.Observando a Tabela 4, é possível perceber que a variável independente $\mathrm{CH} 3$ (coloca em prática as ideias dos vendedores) está associada positivamente à variável dependente $Y$ (satisfação com o trabalho), isto é, os dados indicam que o fato do chefe colocar em prática as ideias dos vendedores afeta positivamente a satisfação dos vendedores com o trabalho. Sendo assim, pode-se afirmar que quanto mais o chefe colocar as ideias dos vendedores em prática, maior será a satisfação dos vendedores com o trabalho. A variável independente $\mathrm{CH} 4$ (justo com o vendedor) também afeta positivamente a variável dependente $Y$ (satisfação com o trabalho), ou seja, quanto menos o vendedor sofrer com injustiças no trabalho vindas do chefe, maior será a satisfação dele com o trabalho. A justiça e a integridade do chefe vão depender da confiança que o vendedor tem no chefe (Mulki, Jaramillo, \& Locander, 2006). 
Tabela 4:

Coeficientes obtidos na regressão

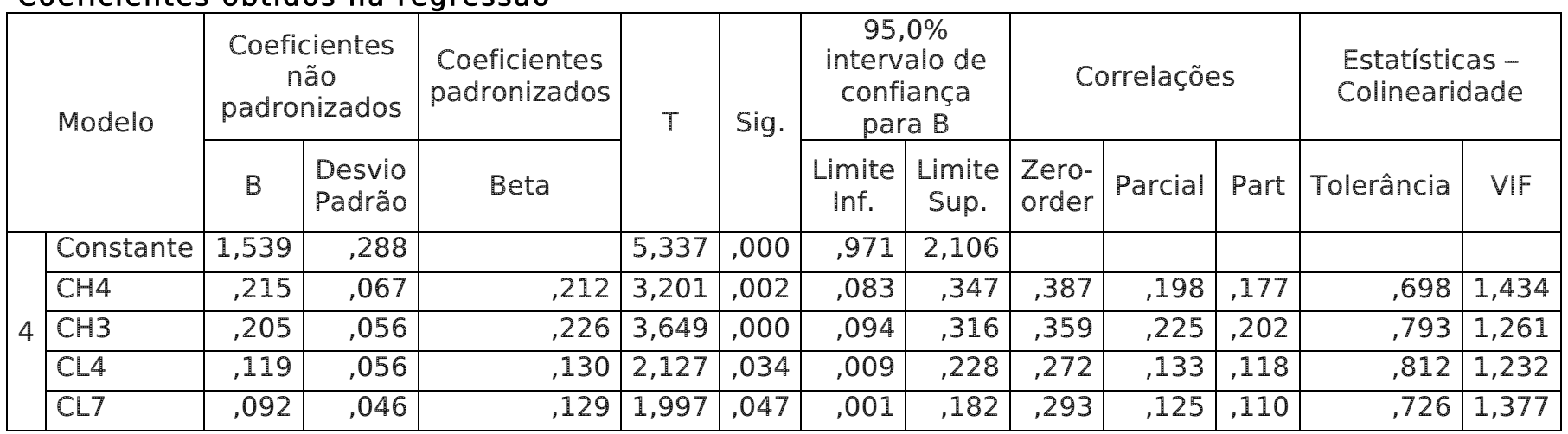

Nota. Fonte: Dados da Pesquisa

Obs: Variável dependente: $Y$

A importância das atitudes que o chefe possui sobre as decisões dos vendedores, pesquisada por autores como Churchill, Ford e Walker (1974) e Stan et al. (2012), foi evidenciada nesse modelo de regressão. Para se ter vendedores satisfeitos com o trabalho é preciso ter chefes que saibam desenvolver muito bem as suas funções. Aos olhos dos vendedores, o chefe é o alicerce dele no trabalho, pois é o chefe que direciona suas ações de vendas. Muitos dos vendedores se espelham no chefe com diferentes intuitos, por exemplo, de agradá-lo, de se sobressair perante aos outros vendedores e também de futuramente conseguir um cargo melhor no trabalho. Segundo Mackenzie e Podsakoff (2001), os chefes que conseguirem exercer adequadamente a liderança e envolver os vendedores, de forma que os objetivos e as aspirações de todos se tornem um só, provavelmente terão vendedores mais satisfeitos e com mais vontade de trabalhar. Os vendedores tendem a respeitar os gestores que são justos com eles e que têm altos padrões de conduta ética (Mulki, Jaramillo, \& Locander, 2006). Além disso, os chefes, quando são eficazes, afetam os representantes de vendas e o processo pelo qual os vendedores iniciam, desenvolvem e ampliam o relacionamento com os clientes (Deeter-Schmelz, Goebel, \& Kennedy, 2008).

Observando novamente os dados da Tabela 4, nota-se que a variável independente CL4 (confiança) está associada positivamente a variável dependente Y (satisfação com o trabalho). É possível sugerir que, quanto maior a demonstração de confiança do cliente, maior será a satisfação dos vendedores com o trabalho. Clientes confiáveis fazem exatamente o que falam e são rentáveis para o negócio (Punwatkar \& Verghese, 2014). Esse tipo de cliente é muito bom para os vendedores, principalmente para aqueles que recebem remuneração variável. Segundo o estudo de Punwatkar e Verghese (2014), como um vendedor permanece em constante interação com um ou outro cliente, ele deve ser eficiente em certos aspectos comportamentais, de modo que um cliente possa ser moldado e se tornar um cliente confiável. Clientes bem tratados e satisfeitos, não só com o produto ou serviço, mas também com o atendimento, gradualmente tendem a se tornar clientes confiáveis e fiéis à empresa, conforme citam Slater e Narver (1995), Punwatkar e Verghese (2014), Stan et al. (2012) e Valentine (2009).

Já a variável independente CL7 (compreensão) também está associada positivamente à variável dependente "satisfação com o trabalho" $(Y)$. Isso mostra que, quanto mais os clientes respeitarem os vendedores, maior será a satisfação deles com o trabalho. Os vendedores, ao se relacionarem com os clientes, necessitam ter comportamento ético, habilidade em escutar, habilidade em se relacionar e inteligência emocional para criar vínculos com o cliente e conseguir realizar a venda. Além disso, de acordo com Punwatkar e Verghese (2014), os vendedores, em sua maioria, enxergam a relação que têm com os clientes como algo mútuo, em que é solicitado aos vendedores que eles atendam aos clientes respeitando os bons princípios morais. Em contrapartida, eles também querem que os clientes os tratem com base nos mesmos princípios. Em resumo, segundo os respondentes, a satisfação do vendedor com o seu trabalho é afetada por determinados comportamentos dos chefes e dos clientes. Se tais comportamentos estiverem presentes no dia a dia do vendedor, este possivelmente estará satisfeito com o seu trabalho.

Os resultados encontrados, por meio da regressão, têm importantes implicações para a compreensão da satisfação com o trabalho em vendas. A contribuição desse estudo foi evidenciar a associação que as dimensões chefe e cliente possuem sobre a satisfação dos vendedores com o trabalho, em especial o chefe. Por meio dos resultados da regressão, é possível sugerir que as variáveis independentes relacionadas à percepção que os vendedores possuem dos chefes são as mais relevantes para a satisfação com o trabalho (Y). O estudo de Mulki, Jaramillo e Locander (2006) confirma esse dado, ao afirmar que um importante e fundamental fator da satisfação com o trabalho é a presença de liderança (chefe) e a confiança que o vendedor tem no chefe. Os vendedores, 
quando confiam nos chefes, se sentem seguros e desenvolvem a lealdade à organização e a satisfação com o trabalho.

Por fim, esse estudo possibilitou acrescentar elementos à compreensão já existente na literatura a respeito da satisfação de vendedores com o trabalho. Após as análises da regressão, constatou-se por meio da significância das variáveis, que o chefe e o cliente realmente afetam a satisfação dos vendedores com o trabalho.

\section{Conclusão}

Neste estudo, foi verificado se as atitudes dos chefes e dos clientes afetam a satisfação do vendedor com o trabalho. Para tanto, testou-se um modelo de regressão linear para avaliar essa associação. Os resultados apontaram que a satisfação com o trabalho pode ser afetada por determinadas atitudes dos chefes, tais como colocar em prática as ideias dos vendedores e ser justo; e também pelas atitudes dos clientes em relação à confiança no vendedor e a compreensão em relação ao seu trabalho. Esses resultados corroboram com os estudos de Churchill Jr, Ford e Walker Jr (1974), Futrell (1979), Childers e Ferrel (1979), Nonis e Erdem (1997), Rutherford (2009) e Punwatkar e Verghese (2014).

Além disso, em termos práticos, os resultados do estudo podem auxiliar os gestores a definirem suas políticas de gestão de vendas considerando as relações entre chefe e vendedor, de modo a melhorar a eficácia dessas relações (Mackenzie; Podsakoff \& Rich, 2001). Recomenda-se, portanto, que os chefes tenham mais atenção às suas atitudes e estabeleçam melhor relacionamento com os vendedores, colocando em prática as ideias que os vendedores dão no trabalho, de forma que consigam gerar motivação e comprometimento da força de vendas na organização.

Outro aspecto a ser ressaltado é que pesquisas como esta podem contribuir para que os chefes se capacitem e melhorem sua gestão, prestando mais atenção ao seu comportamento de liderança (Mackenzie; Podsakoff, \& Rich, 2001). Recomenda-se, portanto, que os chefes tenham mais atenção às suas atividades e desenvolvam um melhor relacionamento com os vendedores, colocando em prática as ideias que os vendedores dão no trabalho.

Como limitação do estudo, evidencia-se que sua aplicação se deu com vendedores apenas do Estado do Espírito Santo, portanto, a replicação dele em outros Estados brasileiros poderia auxiliar a entender de forma mais abrangente como as atitudes dos chefes e dos clientes afetam a satisfação dos vendedores com o trabalho em PME brasileiras. Outra limitação é a aplicação parcial da escala INDSALES, pois utilizou-se apenas 2 das 7 dimensões existentes da satisfação com o trabalho. Entretanto, o uso parcial da escala auxiliou os pesquisadores a obterem mais respostas dos vendedores, que tendem a ficar menos cansados ao responderem um questionário menor (Comer, Machleit \& Lagace, 1989).

$\mathrm{Na}$ intenção de ampliar a discussão sobre os resultados encontrados, sugere-se que em estudos futuros sejam estudadas as outras cinco dimensões da satisfação com o trabalho presentes na escala INDSALES. Estudos futuros também podem mensurar, utilizando a versão original da INDSALES, se há associação entre as sete dimensões da escala e a satisfação de vendedores com o trabalho ou com o comprometimento organizacional. Ainda sobre o comprometimento organizacional do vendedor, sugere-se que em estudos posteriores, verifique se o mesmo está correlacionado às dimensões Promoção e Salário.

A importância da associação do papel do chefe com a satisfação do vendedor no trabalho abre caminhos para novas pesquisas que investiguem em estudos futuros as consequências da liderança exercida pelo chefe, a relação dessa liderança exercida sobre o vendedor e o desempenho do vendedor no trabalho e até mesmo a associação das atitudes do chefe e da satisfação com o trabalho em aspectos da vida pessoal do vendedor.

\section{Notas}

1. Nós agradecemos aos avaliadores anônimos, que muito contribuíram para a melhoria do trabalho aqui apresentado.

\section{Referências}

Amyx, D., \& Bhuian, S.(2009). Salesperson: the salesperson service performance scale. Journal of Personal Selling and Sales Management, 29(4), 367-376. 
Bartkus, K. R., Peterson, M. F., \& Bellenger, D. N. (1989). Type a behavior, experience, and salesperson performance. Journal of Personal Selling \& Sales Management, 9(2), 11-18.

Boles, J., Madupalli, R., Rutherford, B., \&Wood, J. A. (2007). The relationship of facets of salesperson job satisfaction with affective organizational commitment. Journal of Business \& Industrial Marketing, 22(5), 311-321.

Boulding, W., Kalra, A., Staelin, R., \& Zeithaml, V. (1993). A dynamic process model of service quality: from expectations to behavioral intentions. Journal of Marketing Research, 30(1), 7-27.

Childers, T. L., \& Ferrell, O.C. (1979). Response rates and perceived questionnaire length in mail surveys. Journal of Marketing Research, 16(3), 429-431.

Churchill, G. A., Jr., Ford, N. M., \&Walker, O. C., Jr. (1974). Measuring the job satisfaction of industrial salesmen. Journal of Marketing Research, 11(3), 254-260.

Comer, J. M., Machleit, K. A., \&Lagace, R. R. (1989). Psychometric assessment of a reduced version of INDSALES. Journal of Business Research, 18(4), 291-302.

Deeter-Schmelz, D. R., Goebel, D.J., \& Kennedy, K. N. (2008). What are the characteristics of an effective sales manager? An exploratory study comparing salesperson and sales manager perspectives.Journal of Personal Selling \& Sales Management, 28(1), 7-20.

Departamento Intersindical de Estatística e Estudos Socioeconômicos - DIEESE. (2009). Comércio em 2009: Um balanço dos principais indicadores. Rio de Janeiro, 2010. Recuperado em 01 de março, 2014, de http://www.dieese.org.br/estudosepesquisas/2010/estPesq52BalancoComercio.pdf

Erevelles, S., \&Fukawa, N. (2013). The role of affect in personal selling and sales management. Journal of Personal Selling and Sales Management, 33(1), 7-24.

Futrell, C. M. (1979).Measurement of salespeople's job satisfaction: convergent and discriminant validity of corresponding INDSALES and job descriptive index scales. Journal of Marketing Research, 16(4), 594-597.

Goebel, D, J., Deeter-Schmelz, D. R., \&Kennedy, K. N. (2013). Effective sales management: what do sales people think? Journal of Marketing Development \& Competitiveness, 7(2), 11-21.

Hair, J. F., Jr., Babin, B., Money, A. H., \& Samouel, P. (2005). Fundamentos demétodos de pesquisa em administração.Porto Alegre: Bookman.

Jones,E., Brown, S. P., Zoltners, A. A.; \&Weitz, B. A. (2005).The changing environment of selling and sales management. Journal of Personal Selling and Sales Management, 25(2), 105-111.

Kantak, D. M., Futrell, C. M., \& Sager, J. K. (1992).Job satisfaction and life satisfaction in a sales force. Journal of Personal Selling \& Sales Management, 12(1), 1-7.

Koppitsch, S.; Folkes, V. S.; Macinnis, D.; \&Porath, C. (2013). The way a salesperson manages service providers influences customers' anger about problems. Journal of Personal Selling \& Sales Management, 33(1), 67-77.

Lagace, R. R., Goolsby, J. R., \& Gassenheimer, J. B. (1993). Scaling and measurement: a quasireplicative assessment of a revised version of INDSALES. Journal of Personal Selling \& Sales Management, 13(1), 65-72.

Locke, E. A. (1976). The nature and causes of job satisfaction. In M. D. Dunnette. (Ed.). Handbook of Industrial and Organizational Psychology. Chicago: Rand.

Mackenzie, S. B., Podsakoff, P. M., \& Rich, G.A. (2001). Transformational and transactional leadership and salesperson performance. Journal of the Academy of Marketing Science, 29(2), 115-134.

Mantel, S. P. (2005). Choice or perception: How affect influences ethical choices among salespeople. Journal of Personal Selling and Sales Management, 25(1), 44-55.

Mcneilly, K., \&Goldsmith, R. E. (1991). The moderating effects of gender and performance on job satisfaction and intentions to leave in the sales force. Journal of Business Research, 22(3), 219-232.

Mulki, J. P., Jaramillo, F., \&Locander, W. B. (2006). Effects of ethical climate and supervisory trust on salesperson's job attitudes and intentions to quit. Journal of Personal Selling \& Sales Management, 26(1), 19-26.

Nonis, S. A., \&Erdem, S. A. (1997). A Refinement of INDSALES to measure job satisfaction of sales personnel in general marketing settings. Journal of Marketing Management, 7(1), 34-46.

Punwatkar, S., \&V.Manoj. (2014). The impact of salesperson's behavior on consumer's purchase decision: an empirical study. IUP Journal of Marketing Management, 13(2), 72-83. 
Rutherford, B., Boles, J., Hamwi, G. A., Madupalli, R., \&Rhterford, L. (2009). The role of the seven dimensions of job satisfaction in salesperson's attitudes and behaviors. Journal of Business Research, 62(11), 1146-1151.

Shoemaker, M. E. (2001). A framework for examining IT-enabled market relationships. Journal of Personal Selling \& Sales Management, 21(2), 177-185.

Slater, S. F., \& Narver, J. C. (1995). Market orientation and the learning organization. The fournal of Marketing, 59(3), 63-74.

Spagnoli, P., Caetano, A., \&Santos, S. C. (2012).Satisfaction with job aspects: do patterns change over time? Journal of Business Research, 65(5), 609-616.

Spector, P. E. (1997). Job satisfaction: application, assessment, causes, and consequences. Thousand Oaks, CA: Sage.

Spiro, R. L., \& Weitz, B. A. (1990). Adaptive selling: conceptualization, measurement, and nomological validity. Journal of Marketing Research, 27(1), 61-69.

Stan, S., Evans, K. R., Arnold, T. J., \& Mcamis, G. T. (2012). The moderating influence of organizational support on the development of salesperson job performance: can an organization provide too much support? Journal of Personal Selling and Sales Management, 32(4), 405-420.

Valentine, S. (2009). Ethics training, ethical context, and sales and marketing professionals' satisfaction with supervisors and coworkers. Journal of Personal Selling \& Sales Management, 29(3), 227-242.

Yang, L. W., Hansen, J. M., Chartrand, T. L., \&Fitzsimons, G. J. (2013). Stereotyping, affiliation, and self-stereotyping of underrepresented groups in the sales force. Journal of Personal Selling and Sales Management, 33(1), 105-116. 